\title{
$\mathrm{T}-\mathrm{La}_{2-x} \mathrm{Y}_{x} \mathrm{CuO}_{y}$ 薄膜の相, 格子定数及び導電率の組成及びアニール条件依存性
}

\author{
井手本 康 · 宮部 徹 · 小浦延幸 \\ 東京理科大学理工学部工業化学科, 278-8510 野田市山崎 2641
}

\section{Dependence of Phase, Lattice Constants, and Conductivity on the Composition and Annealing Conditions of $\mathrm{T}^{-\mathrm{La}_{2-x}} \mathrm{Y}_{x} \mathrm{CuO}_{y}$ Thin Film}

\author{
Yasushi IDEMOTO, Toru MIYABE and Nobuyuki KOURA \\ Department of Pure and Applied Chemistry, Faculty of Science and Technology, Tokyo University of Science, \\ 2641, Yamazaki, Noda-shi, Chiba 278-8510
}

\begin{abstract}
We prepared $\mathrm{T}-\mathrm{La}_{2-x} \mathrm{Y}_{x} \mathrm{CuO}_{y}$ thin film using the spin coating-pyrolysis method. We then investigated the relationship between the phase, lattice constants, and conductivity with the changing oxygen content using heat treatment. The lattice constant, $c$, decreased and conductivity increased with the decreasing $\boldsymbol{P}_{\mathbf{O}_{2}}$. Although the resistivity of most thin films decreased remarkably at less than $60 \mathrm{~K}$, they did not exhibit zero resistivity.
\end{abstract}

[Received October 31, 2005; Accepted January 19, 2006]

Key-words : Thin film, Substitution effect, $(\mathrm{La}, \mathrm{Y})-214$ system, Conductivity, Spin coating-pyrolysis method, T-structure, Oxygen content

\section{1. 緒 言}

$\mathrm{La} 214$ 系超伝導酸化物は，Y 系， Bi 系， $\mathrm{Tl}$ 系などの高温超 伝導酸化物に比べて構造が比較的単純でペロブスカイト層と岩 塩層の積層構造をとり，また $\mathrm{La}_{2-x} \mathrm{Ba}_{x} \mathrm{CuO}_{4-\delta}$ に扔いて $1 / 8$ 異 常といった興味深い現象もみられるため, 種々の研究が行われ ている．本系は，銅サイトの酸素の配位数によって， $\mathrm{T}$ 構造 (八面体 6 配位), $\mathrm{T}^{*}$ 構造 $\left(5\right.$ 配位), $\mathrm{T}^{\prime}$ 構造 (平面 4 配位), 9 3 種類の結晶構造をとる. $\mathrm{T}$ 構造は $\mathrm{La}_{2} \mathrm{CuO}_{4}$ の $\mathrm{La}$ サイトに 2 価の $\mathrm{Ba}, \mathrm{Sr}, \mathrm{Ca}$ を一部置換し超伝導となるホールドープ型1),2), $\mathrm{T}^{*}$ 構造は $\mathrm{Nd}$ サイトに 4 価の $\mathrm{Ce}$ を， Ba サイトに 3 価の $\mathrm{Nd}$ を 一部置換することで超伝導になるホールドープ型 ${ }^{3)}, \mathrm{T}^{\prime}$ 構造は $\mathrm{Nd}_{2} \mathrm{CuO}_{4}$ の $\mathrm{Nd}$ サイトに 4 価の $\mathrm{Ce}$ を一部置換し超伝導となる 電子ドープ型 4$)$ ，の 3 種類の高温超伝導酸化物が知られてい る.これらの構造の安定性は, ペロブスカイト構造の $\mathrm{A}$ サイ 卜に位置する希土類元素のイオン半径によって決まり，イオン 半径の大きな $\mathrm{La}$ では $\mathrm{T}$ 構造が安定化し，イオン半径が小さな 他の希土類元素では $\mathrm{T}^{\prime}$ 構造が安定化する. 最近, MBE 法に よって $\mathrm{T}^{\prime}-\mathrm{La}_{2} \mathrm{CuO}_{4}$ の薄膜が作製され ${ }^{5)}$ ，更に価数変化がない $\mathrm{RE}(=\mathrm{Y}, \mathrm{Sm}, \mathrm{Eu}, \mathrm{Gd}, \mathrm{Tb}, \mathrm{Lu})$ を置換させても薄膜で超伝導に なることが報告された ${ }^{6)}$ 。しかし，その機構，要因はまだ明ら かではない。

薄膜では分析が困難な銅の価数, 酸素量と導電率の関係を検 討するために，著者らは，これまでに $\mathrm{T}$ 構造の $\mathrm{La}_{2-} \mathrm{RE}_{x} \mathrm{CuO}_{y}$ $(\mathrm{RE}=\mathrm{Y}, \mathrm{Tb})$ のバルク体を作製し, 物性, 構造と導電性の関 係について検討し，更に超伝導性の有無についても併せて検討 してきた．その結果， $\mathrm{T}$ 構造の $\mathrm{La}_{2-x} \mathrm{RE}_{x} \mathrm{CuO}_{y}(\mathrm{RE}=\mathrm{Y}, \mathrm{Tb})$ に拈いては，酸素量が減少するのに伴い，導電率が向上し，い ずれも抵抗率が急落する現象がみられたがゼロ抵抗を示すには 至らなかった ${ }^{7)}$ 。そこで，薄膜化することにより，これらの挙 動が変化するかを検討するため, 本研究では, 塗布熱分解法に より $\mathrm{T}$ 構造の $\mathrm{La}_{2-x} \mathrm{Y}_{x} \mathrm{CuO}_{y}$ 薄膜を新たに作製し，置換量，熱 処理に伴う物性, 導電性の変化を比較, 検討した。更に，基板 を変えたときの影響についても併せて比較，検討した．

\section{1 薄膜の作製}

\section{2. 実験方法}

$\mathrm{La}_{2-x} \mathrm{Y}_{x} \mathrm{CuO}_{y}$ 薄膜は，ナフテン酸を用いた塗布熱分解法で作 製を行った ${ }^{8)}$. ファクター決定を行った日本化学産業製の $\mathrm{La}$, $\mathrm{Y}, \mathrm{Cu}$ のナフテン酸塩トルエン溶液を所定比で混合し, スピ ナーを使用して $10 \mathrm{~mm} \times 10 \mathrm{~mm} \times 0.5 \mathrm{~mm}$ の $\mathrm{MgO}(100), \mathrm{SrTiO}_{3}$ (100), $\mathrm{YAlO}_{3}$ (110) 単結晶基板上に塗布した。基板上に混合溶 液を滴下し，スピナーにより $4000 \mathrm{rpm}, 6 \mathrm{~s}$ 塗布し， $200^{\circ} \mathrm{C}, 10$ $\min$ 乾燥を行い, $500^{\circ} \mathrm{C}$, 空気中, $10 \mathrm{~min}$ 熱分解を行った. こ の工程を 10 回繰り返した後, 本焼成は $9000^{\circ} \mathrm{C}$, 空気中, $10 \mathrm{~min}$ 行い, $\mathrm{La}_{2-x} \mathrm{Y}_{x} \mathrm{CuO}_{y}[x=0.05,0.10,0.15 ; \mathrm{MgO}(100)], \mathrm{La}_{1.90}$ $\mathrm{Y}_{0.10} \mathrm{CuO}_{y}\left[\mathrm{SrTiO}_{3}(100)\right], \mathrm{La}_{1.90} \mathrm{Y}_{0.10} \mathrm{CuO}_{y}\left[\mathrm{YAlO}_{3}(110)\right]$ 薄膜

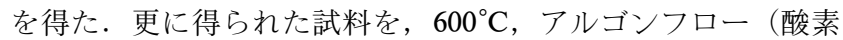
分圧 : $10^{-1.5} \mathrm{~Pa}$ ）で, $10 \mathrm{~min}$ 又は $500 \sim 550^{\circ} \mathrm{C}, 10^{-4} \mathrm{~Pa}$ の減压 下 5 min アニールを行うことにより酸素量を制御した.

\section{2 試料の相の同定, 格子定数及び組成}

$\mathrm{X}$ 線回折（Philips 製，X’Pert Pro, $\mathrm{Cu} \mathrm{K} \alpha$ 線）により相の同 定, 格子定数を求めた。 また, ICPにより金属成分の組成を決 定した。

\section{3 導電率の測定}

導電率は直流四端子法により, 室温から $4.2 \mathrm{~K}$ まで測定を行っ た．測定用プローブの熱電対は $\mathrm{Au}(0.07 \% \mathrm{Fe})-\mathrm{Ag}$ を用い，測 定温度間隔は通常 $2 \mathrm{~K}$ に設定し, 抵抗率が低下する温度付近で は $0.5 \mathrm{~K}$ とした. 抵抗率測定時の印加電流は $3 \mathrm{~mA}$ とした.

\section{3. 結果及び考察}

$\mathrm{La}_{2-x} \mathrm{Y}_{x} \mathrm{CuO}_{y}$ 薄膜について, $\mathrm{MgO}(100)$ [格子定数, $a=$ $0.4212 \mathrm{~nm}]$ 単結晶基板上に $x=0.05,0.10,0.15$ の薄膜を作製し, 更に $\mathrm{SrTiO}_{3}(100)$ [格子定数, $a=0.3905 \mathrm{~nm}$ ] 及び $\mathrm{YAlO}_{3}(110)$ [格子定数, $a=0.3715 \mathrm{~nm}$ ] 単結晶基板上に $x=0.10$ の薄膜を作 製した．X 線回折測定により相の同定を行い，格子定数を決定 した。得られた X 線回折パターンを図 1 に示す。いずれも $\mathrm{T}$ 構造の単一相が得られた. 得られた試料の $\mathrm{Y}$ 置換量と格子定数 の関係を図 2 に示す。 $\mathrm{MgO}(100)$ 単結晶基板上に作製した薄膜 


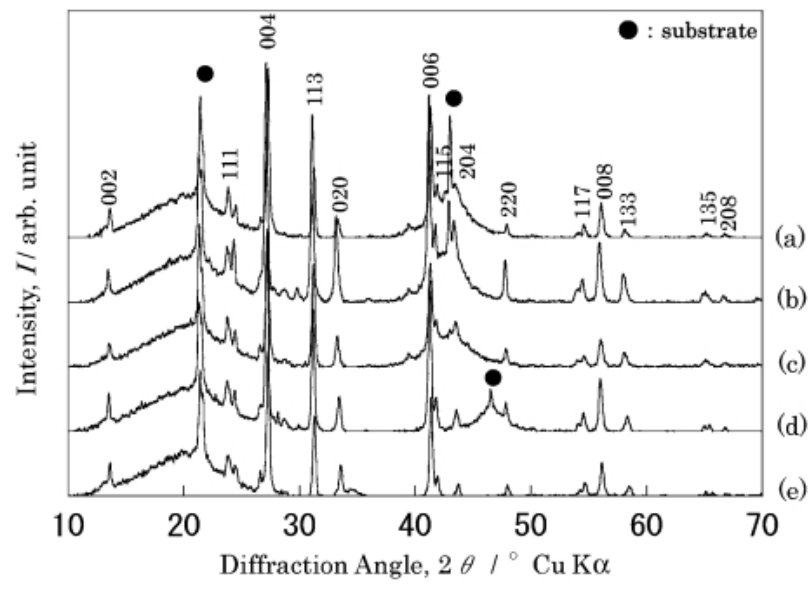

Fig. 1. X-ray diffraction patterns $\mathrm{La}_{2-x} \mathrm{Y}_{x} \mathrm{CuO}_{y}$ thin films. (a) $x=0.05$ ( $\mathrm{MgO}$ substrate), (b) $x=0.10$ (MgO substrate), (c) $x=$ $0.15(\mathrm{MgO}$ substrate $),(\mathrm{d}) x=0.10\left(\mathrm{SrTiO}_{3}\right.$ substrate $),(\mathrm{e}) x=0.10$ ( $\mathrm{YAlO}_{3}$ substrate $)$.

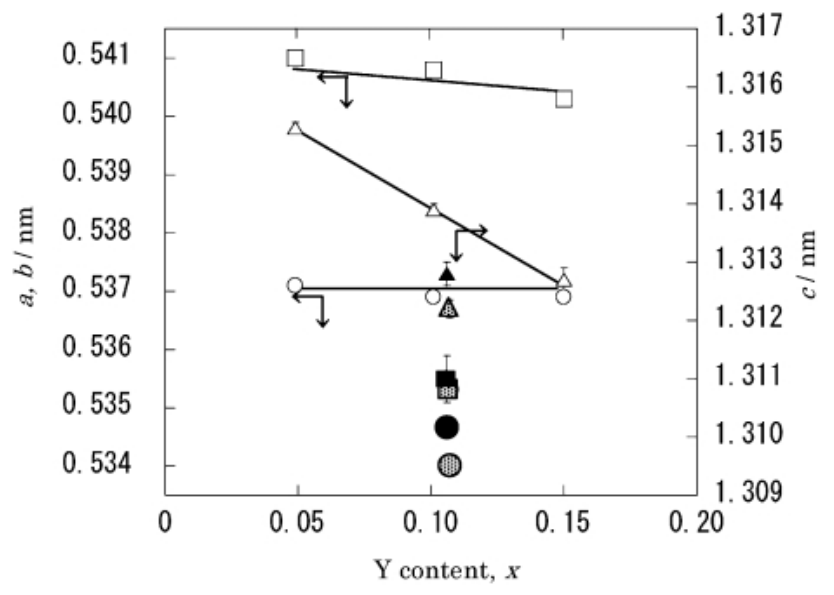

Fig. 2. Relation between $c$-axis and $\mathrm{Y}$ content, $x$ of $\mathrm{La}_{2-x} \mathrm{Y}_{x} \mathrm{CuO}_{y}$ thin films.

$\mathrm{La}_{2-x} \mathrm{Y}_{x} \mathrm{CuO}_{y}(\mathrm{MgO}$ substrate $) \bigcirc a$-axis, $\square b$-axis, $\triangle c$-axis $\mathrm{La}_{1.90} \mathrm{Y}_{0.10} \mathrm{CuO}_{y}\left(\mathrm{SrTiO}_{3}\right.$ substrate $) a$-axis, $b$-axis, $\mathbf{\Delta} c$-axis $\mathrm{La}_{1.90} \mathrm{Y}_{0.10} \mathrm{CuO}_{y}\left(\mathrm{YAlO}_{3}\right.$ substrate $)(1) a$-axis, 畋 $b$-axis, $c$-axis

について, $\mathrm{Y}$ 置換量 $x$ が増加するに伴い $a, b$ 軸長は若干減少, $c$ 軸長は減少する傾向がみられた。 バルク体 ${ }^{7)}$ と同様に $c$ 軸長

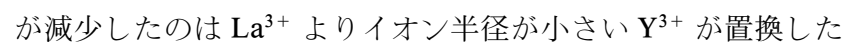
ことによると考えられる. また, $\mathrm{MgO}(100)$ 単結晶基板上に作 製した薄膜に比べて $\mathrm{SrTiO}_{3}(100)$ 単結晶基板, $\mathrm{YAlO}_{3}(110)$ 単結 晶基板上に作製した薄膜は $c$ 軸長が短くなった．更に， $a, b$ 軸 長も短く両者の差も小さくなった。これは $\mathrm{MgO}$ 単結晶基板に 比べて $\mathrm{SrTiO}_{3}$ 単結晶基板, $\mathrm{YAlO}_{3}$ 単結晶基板は $a$ 軸長が短 く，基板上に作製した薄膜がその影響を受けたものと考えられ る.これらの試料の金属成分の組成を ICP 発光分光分析によ り決定し，得られた結果を表 1 に示す。ここで，金属成分の合 計は 3 となるように組成を求めた。この結果，仕込組成通りに ほぼ制御された試料が得られた。

更にこれらの試料について還元アニールを行った。一例とし て $\mathrm{Y}$ 置換量 $x=0.10\left[\mathrm{SrTiO}_{3}(100)\right]$ のアニールを行った試料の $\mathrm{X}$ 線回折パターンを図 3 に示す．いずれの試料も真空下 $\left(10^{-4}\right.$ $\mathrm{Pa})$ に扔いて, $550^{\circ} \mathrm{C}$ 以上でアニールを行うと分解し $\mathrm{Y}_{2} \mathrm{O}_{3}$ が
Table 1. Analytical Composition of the Pre-Annealed and Annealed $\mathrm{La}_{2-x} \mathrm{Y}_{x} \mathrm{CuO}_{y}$ Thin Films

\begin{tabular}{cccc}
\hline $\mathrm{Y}$ content, $\mathrm{x}$ & \multicolumn{3}{c}{ Comopition } \\
\cline { 2 - 4 } & $\mathrm{La}$ & $\mathrm{Y}$ & $\mathrm{Cu}$ \\
\hline $\mathrm{x}=0.05(\mathrm{MgO})$ & $1.954(3)$ & $0.049(2)$ & $0.997(5)$ \\
$\mathrm{x}=0.10(\mathrm{MgO})$ & $1.905(1)$ & $0.101(1)$ & $0.994(4)$ \\
$\mathrm{x}=0.15(\mathrm{MgO})$ & $1.847(3)$ & $0.150(4)$ & $1.003(1)$ \\
$\mathrm{x}=0.10\left(\mathrm{MgO}^{*}\right.$ & $1.907(4)$ & $0.099(4)$ & $0.994(5)$ \\
$\mathrm{x}=0.10\left(\mathrm{SrTiO}_{3}\right)$ & $1.898(1)$ & $0.106(2)$ & $1.004(1)$ \\
$\mathrm{x}=0.10\left(\mathrm{YAlO}_{3}\right)$ & $1.895(3)$ & $0.107(1)$ & $0.998(4)$ \\
\hline & $*$ annealed at $500^{\circ} \mathrm{C}, 10^{-4} \mathrm{~Pa}, 5 \min$ &
\end{tabular}

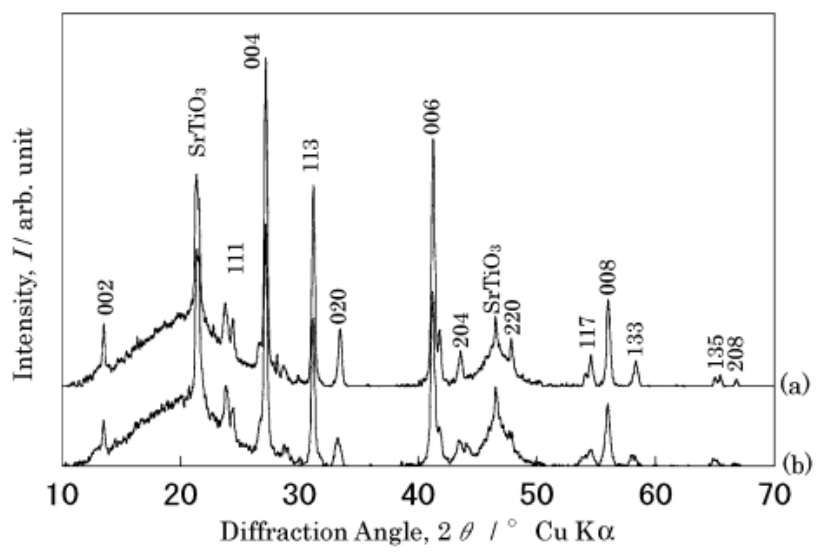

Fig. 3. X-ray diffraction patterns of $\mathrm{La}_{1.90} \mathrm{Y}_{0.10} \mathrm{CuO}_{y}$ thin films $\left(\mathrm{SrTiO}_{3}\right.$ substrate $)$.

(a) Pre-annealed, (b) $500^{\circ} \mathrm{C}, 10^{-4} \mathrm{~Pa}, 5$ min annealed.

生成した．これらの分解温度を超えなければ，本焼試料と構造 の変化がない単一相が得られた。次に, 還元方向へアニールを 行った試料の導電性を検討した. 得られた抵抗率の温度依存を 図 4 に示す. 大半は金属的な挙動を示し, $60 \mathrm{~K}$ 以下で抵抗率が 急落する試料もみられたが, バルク体と同様にゼロ抵抗は示さ なかった。 また, $\mathrm{MgO}(100)$ 単結晶基板上に作製し, 真空下 $\left(10^{-4} \mathrm{~Pa}\right)$ でアニールを行った試料は抵抗率が低温でも下がら ず，これは基板とのフィッティングの悪さが影響していると考 えられる. 薄膜は, 得られる試料量が極めて少ないため, 化学 分析による価数分析が困難であり, 試料中の酸素量を正確に求 めることは難しい。ここで, 還元アニールを行うのに伴い $c$ 軸 長が減少する傾向がみられ, バルク体の酸素量の減少に伴うそ の傾向 ${ }^{7)}$ と一致した．そこで, 薄膜では酸素量 $y$ に相当するパ ラメーターとして $c$ 軸長を用いた。 得られた $c$ 軸長と導電率の 関係を図 5 に示す。いずれの温度においても $c$ 軸長（酸素量） の減少に伴い導電率は向上した.ここで, $\mathrm{MgO}(100)$ 単結晶基 板に颃いて導電率が高かった $\mathrm{Y}$ 置換量 $x=0.10$ を $\mathrm{SrTiO}_{3}(100)$ 単結晶基板上に作製した薄膜が導電率が最も高かった.これ は, 試料と基板とのフィッティングの良さがその一因と考えら れる。

\section{4. 結 論}

塗布熱分解法により, $\mathrm{T}$ 構造 $\mathrm{La}_{2-x} \mathrm{Y}_{x} \mathrm{CuO}_{y}$ 薄膜の単一相が得 られた.これらについて, 還元方向にアニール処理を行うのに 伴い, $c$ 軸長は減少し, 導電率は向上した. $500^{\circ} \mathrm{C}, 10^{-4} \mathrm{~Pa}$ の 減压下, $5 \mathrm{~min}$ でアニールした $\mathrm{La}_{1.90} \mathrm{Y}_{0.10} \mathrm{CuO}_{y}\left[\mathrm{SrTiO}_{3}(100)\right]$ 


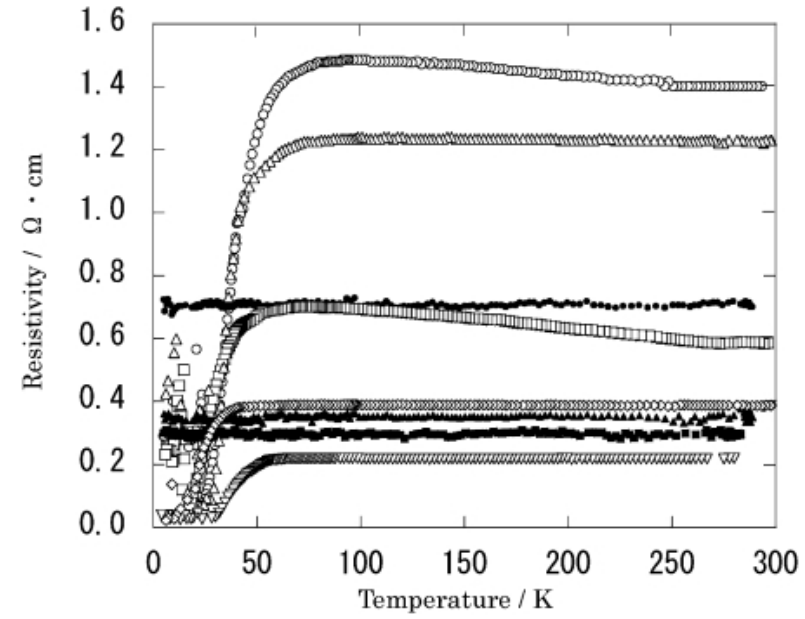

Fig. 4. Relation between resistivity and temperature of $\mathrm{La}_{2-x} \mathrm{Y}_{x}$ $\mathrm{CuO}_{y}$ thin films.
O : $\mathrm{La} 1.95 \mathrm{Y}_{0.05} \mathrm{CuO}_{y}$ ( $\mathrm{MgO}$ substrate) $\left(600^{\circ} \mathrm{C}, \mathrm{Ar}, 10 \mathrm{~min}\right.$ annealed)
- : La ${ }_{1.95} \mathrm{Y}_{0.05} \mathrm{CuO}_{y}$ (MgO substrate) $\left(600^{\circ} \mathrm{C}, 10^{-4} \mathrm{~Pa}, 5 \mathrm{~min}\right.$ annealed)
$\square: \mathrm{La}_{1.90} \mathrm{Y}_{0.10} \mathrm{CuO}_{\mathrm{y}}$ (MgO substrate) $\left(600^{\circ} \mathrm{C}, \mathrm{Ar}, 10 \mathrm{~min}\right.$ annealed)
- : $\mathrm{La}_{1.90} \mathrm{Y}_{0.10} \mathrm{CuO}_{\mathrm{y}}(\mathrm{MgO}$ substrate) $\left(600^{\circ} \mathrm{C}, \mathrm{Ar}, 10 \mathrm{~min}\right.$ annealed)
$\triangle: \mathrm{La}_{1.85} \mathrm{Y}_{0.15} \mathrm{CuO}_{y}$ ( $\mathrm{MgO}$ substrate) $\left(600^{\circ} \mathrm{C}, \mathrm{Ar}, 10 \mathrm{~min}\right.$ annealed)
A : $\mathrm{La}_{1.85} \mathrm{Y}_{0.15} \mathrm{CuO}_{y}$ (MgO substrate) $\left(600^{\circ} \mathrm{C}, 10^{4} \mathrm{~Pa}, 5 \mathrm{~min}\right.$ annealed)
$\nabla: \mathrm{La}_{1.90} \mathrm{Y}_{0.10} \mathrm{CuO}_{y}$ ( $\mathrm{SrTiO}_{3}$ substrate) $\left(500^{\circ} \mathrm{C}, 10^{4} \mathrm{~Pa}, 5 \mathrm{~min}\right.$ annealed)
$\diamond: \mathrm{La}_{1.90} \mathrm{Y}_{0.10} \mathrm{CuO}_{y}\left(\mathrm{YAlO}_{3}\right.$ substrate) $\left(500^{\circ} \mathrm{C}, 10^{4} \mathrm{~Pa}, 5 \mathrm{~min}\right.$ annealed)

が $50 \mathrm{~K}$ に抢ける導電率が最も高かった．屯たバルク体と同様に 抵抗率が急落する現象がみられるものもあったがゼロ抵抗を示 すには至らなかった。

\section{References}

1) Bednorz, J. G. and Mueller, K. A., Z. Phys. B, Vol. 64, pp. 189-193 (1986).

2) Kishio, K., Kitazawa, K., Kanbe, S., Yasuda, I., Sugii, N., Takagi, H., Uchida, S., Fueki, K. and Tanaka, S., Chem. Lett., No. 2, pp. 429-432 (1987).

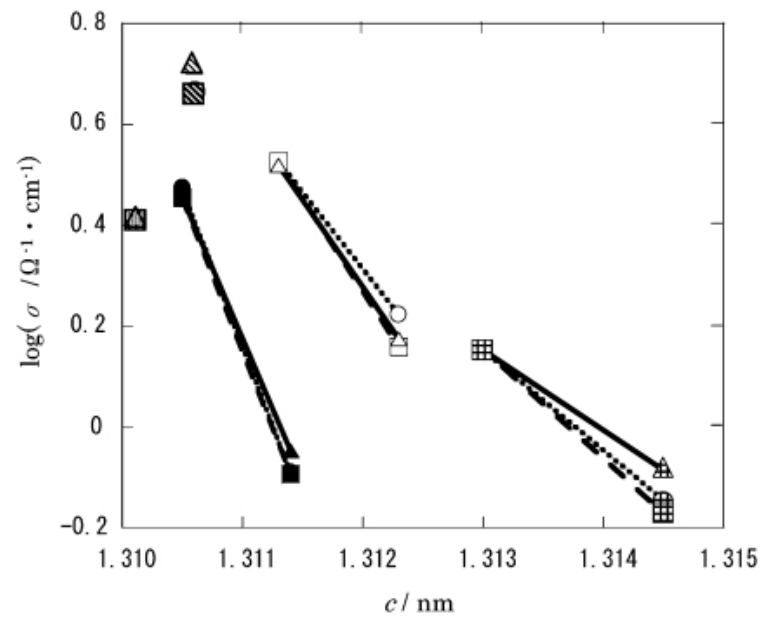

Fig. 5. Relation between $\log \sigma$ and $c$-axis of $\mathrm{La}_{2-x} \mathrm{Y}_{x} \mathrm{CuO}_{y}$ thin films.

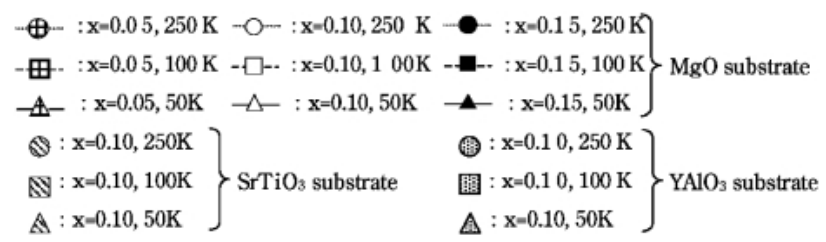

3) Izumi, F., Fujimori, A., Kamiyama, T., Asano, H., Akimitsu, J. and Sawa, H., Physica C, Vol. 158, pp. 440-448 (1989).

4) Takagi, H., Uchida, S. and Tokura, Y., Phys. Rev. Lett., Vol. 62, pp. 1197-1200 (1989).

5) Tsukada, A., Greibe, T. and Naito, M., Phys. Rev. B, Vol. 66, pp. 184515/1-5 (2002).

6) Tsukada, A., Krockenberger, Y., Noda, M., Yamamoto, H., Manske, D., Alff, L. and Naito, M., Solid State Commun., Vol. 133, pp. 427-431 (2005).

7) Idemoto, Y., Miyabe, T. and Koura, N., Material Technology, in press [in Japanese].

8) Idemoto, Y., Matsuura, Y. and Koura, N., J. Ceram. Soc. Japan, Vol. 109, pp. 939-943 (2001) [in Japanese]. 